\title{
Oxytocin and Stress Response
}

\author{
Abeer E. Dief ${ }^{*}{ }^{*}$, Elena V. Sivukhina ${ }^{2}$, Gustav F. Jirikowski² \\ ${ }^{1}$ Department of Medical Physiology, University of Alexandria, Alexandria, Egypt \\ ${ }^{2}$ Institute für Anatomie II, Friedrich Schiller Universität Jena, Jena, Germany \\ Email: *abeer.dief@alexmed.edu.eg
}

How to cite this paper: Dief, A.E., Sivukhina, E.V. and Jirikowski, G.F. (2018) Oxytocin and Stress Response. Open Journal of Endocrine and Metabolic Diseases, 8, 93-104 https://doi.org/10.4236/ojemd.2018.83010

Received: January 22, 2018

Accepted: March 20, 2018

Published: March 23, 2018

Copyright $\odot 2018$ by authors and Scientific Research Publishing Inc. This work is licensed under the Creative Commons Attribution International License (CC BY 4.0).

http://creativecommons.org/licenses/by/4.0/

\begin{abstract}
In response to a stressful unexpected experience, the brain activates a complex stress system that involves the organism in an adaptive response to the threatening situation. This stress system acts on several peripheral tissues and feeds back to the brain. One of its key players is oxytocin hormone. The neuropeptide, oxytocin (OT), has well-established roles during parturition and lactation. In addition to its peripheral actions, OT is released within multiple areas of the brain and influences behavioural and neuroendocrine responses to stress. Several studies suggest that oxytocin is implicated in the central control of responses to stress through modulation of corticotrophin releasing hormone (CRH). Intranasal OT application was associated with an inhibitory effect on adrenocorticotrophic hormone (ACTH) secretion and subsequent impairment of corticosterone secretion. This may be of importance for understanding and perhaps suggesting its utility to buffer stress. Synthesis and release of OT depend to a great extent on steroid hormones particularly on estradiol and corticosterone. Estrogens stimulate synthesis and release of OT and increase the number of OT receptors in some areas of the brain. However, the role of $\mathrm{OT}$ in mediating stress is variable and may also depend on gender and on external factors.
\end{abstract}

\section{Keywords}

Oxytocin, Central Stress Response, Corticotrophin Releasing Hormone, Steroid Hormone, Hypothalamic-Pituitary-Adrenal Axis

\section{Introduction}

Stress is a phenomena associated with daily life. When people facing overwhelming situations, they develop stress reaction. Stressors could be external events either positive or negative or may come from internal feeling that makes 
the person angry or anxious. Stress could be beneficial when it motivates the person to become productive and energetic. However, too much stress is always injurious and results in many psychological and physical defects [1] [2]. Transient stress can elicit adaptive response, however, repeated activation of the stress system exerts deleterious effects on several organ functions including the brain, immune system and the viscera [3]. In facing stressful situations, the human body develops stress response, which involves interaction between different body systems to cope with the stressors. The stress response is a coordinated reaction to threatening stimuli, characterized by avoidance behavior, increased arousal, and stimulation of the sympathetic nervous system with cortisol release. Hypothalamus is centrally involved in coordinating the adequate humoral, visceromotor, and somatic motor responses [4].

\section{Different Components of Stress Response}

The autonomous nervous system and the hypothalamic pituitary adrenal (HPA) axis are mainly the two systems reacting to stress; both systems activate each other in a positive feedback mechanism. Central stress response is mediated by activation of $\mathrm{CRH}$, vasopressin (VP) and OT which in turn stimulate release of ACTH by the anterior pituitary gland [5]. Such OT induced ACTH secretion is inhibited by adrenal glucocorticoid hormones (GC), however regular HPA axis negative feedback, and ACTH secretion is not only induced by OT. ACTH response to OT is variable; OT exerts a synergistic effect on ACTH secretion when applied with either CRH or VP [6]. Therefore, CRH and its functionally related peptides OT and VP are among the key mediators of the stress response whether adaptive or maladaptive depending on dose [3]. Knock out mice with inactivation of CRH receptors in certain brain regions with sparing of the hypothalamus and pituitary receptors showed reduced anxiety behaviour and normal basal activity of HPA. However, their plasma ACTH and corticosterone response to stress were prolonged, reflecting loss of normal negative feedback regulation of HPA axis [7] (Figure 1).

\section{Oxytocin Hormone and Its Receptors}

OT was first described in 1906 by Dale who observed that extracts from the human posterior pituitary gland were able to contract the uterus of a pregnant cat. The name oxytocin came from the Greek words, meaning "swift birth" [8]. The neurohypophyseal nonapeptide OT and its associated neurophysin I (NP1) are mainly synthesized in magnocellular neurons of the paraventricular (PVN) and supraoptic nuclei (SON) of the hypothalamus [9]. OT or its associated NP1 are processed from a common precursor (Prooxytophysin). NP1 is thought to serve as a carrier protein during axonal projection to the posterior pituitary lobe, from which the peptide is secreted into the systemic circulation [10].

In addition to the established functions of $\mathrm{OT}$ as labor-inducing and milk-ejecting hormone, OT is also important as a central neurotransmitter, involved in the 


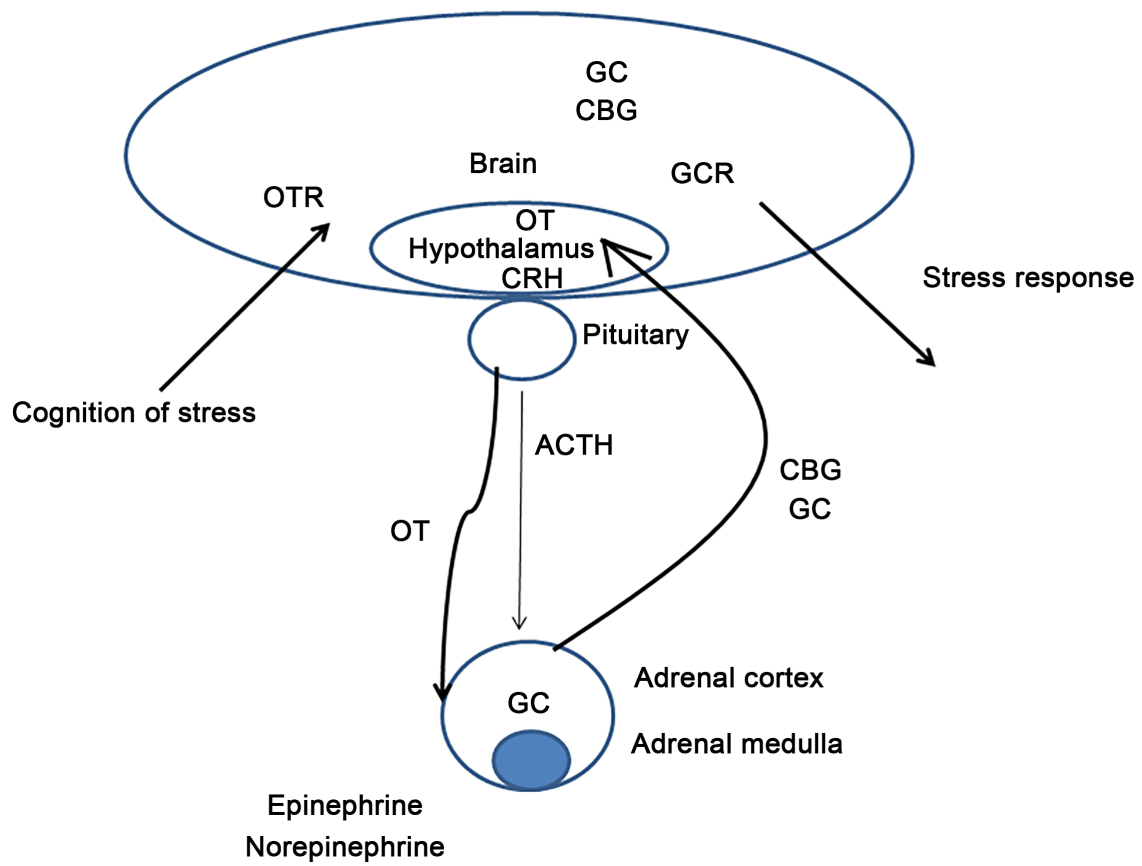

Figure 1. Expression of oxytocin (OT) in the hypothalamic nuclei depends on systemic steroid hormones like glucocorticoids (GC) which are liberated from the adrenal medulla after stimulation by adrenocorticotropic hormone (ACTH) from the anterior pituitary lobe. Hypothalamic corticotropin releasing hormone $(\mathrm{CRH})$ controls ACTH release via oxytocin and its receptors (OTR). Systemic bioavailability of GC depends on hepatic corticosteroid binding globulin (CBG), essential for maintaining systemic stress response, e.g. cardiac function.

central stress response by modulating CRH expression in a dose dependent manner by affecting pituitary corticotrophs through oxytocin receptors (OTRs).

The central actions of OT are mediated by OTRs distributed widely in the brain of different species. Areas containing OTRs exert different effects and therefore were classified into, regions involved in reproductive behaviours (hypothalamic ventromedial nucleus: VMH, PVN), regions involved in maternal behaviours (PVN, substantia nigra, ventral tegmental area), regions involved in learning and memory (hippocampus) and regions involved in reinforcement (substantia nigra, ventral tegmental area, lateral septum, caudate putamen, amygdaloid nuclei, and frontal cortices) [11] [12].

Synthesis and expression of OTRs as well as secretion of OT from hypothalamic or non-hypothalamic source were found to depend in part on gonadal and adrenal steroid levels mediated through nuclear receptors and stimulated gene expression [13]. Systemic surge of estradiol is associated with labour induction and glucocorticoids able to block milk ejection. Oxytocin levels in the serum, and number of OT neurons in the hypothalamus are changed upon oestrogen treatment [14]. Measurable increase in OT levels was observed after estradiol intake in ovariectomized rats. The increased OT secretion in the brain occurred with pregnancy and lactation indicates the positive effect of estrdiol on OT release [15] [16]. 
However, the release of OT from neuronal terminals upon changing steroid level is somewhat fast and cannot be attributed to the classic nuclear steroid receptors. It was found that most of the oxytocinergic neurons in hypothalamic nuclei are devoid of nuclear estrogen receptors, the same was observed for glucocorticoid receptors [14] [17]. Therefore, non-genomic steroid actions through binding globulins or membrane receptors may play a role in such rapid response.

The presence of GCs binding in brain areas such as the amygdala, hippocampus and hypothalamus has been reported by several authors [18] [19]. Immunocytochemical double labelling revealed that numerous glucocorticoid receptor (GR) positive neurons surround OT neurons in rat hypothalamic nuclei, but coexistence of both antigens occurs only rarely, supporting the idea that known rapid GC effects on OT neurons may be non-genomic [17]. We have presented evidence of extensive co-localization of corticosteroid binding globulin (CBG) and OT in the hypothalamus [20] [21] [22]. Although there are high levels of CBG in serum, which is of liver origin [23] [24]. This $52 \mathrm{kDa}$ glycoprotein is unlikely to cross the blood-brain barrier. Central CBG is clearly produced in neurons of the PVN and SON, as demonstrated using RT-PCR. Indeed, CBG is found in a large number of PVN and SON oxytocinergic cells, suggesting intrinsic expression within hypothalamic nuclei [25]. Brain CBG may be involved in membrane actions of GC.

\section{Effects of Endogenous and Exogenous OT on the Social Behaviour}

Evidence from rodent models suggests that both acute and chronic administration of OT reduces physiological and behavioral stress responsiveness [26] [27] [28] [29]. Intranasal administration of OT to alter certain stress response was a matter of intense investigation in many species. Intranasal route of administration has the advantage of direct entry to cerebrospinal fluid by passing the blood brain barrier, thus avoiding undesired hormone like side effects [30]. Intranasal OT is suggested to reach target brain areas such as olfactory bulb and brainstem, which give output to the amygdala [31]. Intracerebroventricular (ICV) injections of OT may reveal similar effects but involve surgical manipulations which per se are stressful. Moreover, it exerted a significant increase in hippocampal neurotrophins and synapsin 1 with enhancement of object recognition [32].

Although it was reported that intranasal OT is able to exert anxiolytic effects in stressed rats and to enhance social interaction [33]. Such effects were found to depend on gender and context, in contrast to male mice. Steinman et al. studied the effect of intranasal OT on behavior in both sexes.

They reported variable effects on stress response in males and females: OT application seemed to induce more anxiogenic reactions in unfamiliar experimental settings and more anxiolytic effects in familiar contexts.

Intranasal OT, had no effect on social interaction behavior in stressed female 
mice [34]. Such observation led to the conclusion that oxytocinergic functions could be estrogen dependent in both sexes [14] [35]. It has been demonstrated that estrogen receptors can directly regulate OT and VP mediated stress pathways due to their anatomical colocalization with these neuropeptides in the PVN [36] [37] [38].

Cohen et al. had reported initial elevation of the basal corticosterone levels after OT infusion in the hippocampus in a rat model of PTSD. However, 2 hours after stress exposure, corticosterone levels were normalized. Additionally, the behavioral response was attenuated at 16 days post-injection of OT, demonstrating a long-lasting effect. Elevation of hippocampal OT was found to attenuate anxiety behavior after predator scent stress (PSS). OT through a feedback mechanism was able to suppress HPA axis thereby terminating the neuroendocrine stress response. GC, on the other hand, were shown to suppress both HPA axis and oxytocinergic system [39] [40]. Although the underlying physiological mechanisms are still a matter of discussion, it seems safe to conclude that OT affected the HPA axis in these experiments.

Winslow et al. reported deficient CSF OT level and agonistic behavior in male monkeys with maternal deprivation at birth [41]. Decrease in OT receptors binding in the amygdala following repeated maternal separation or decreased maternal contact have been reported by several researches [42] [43].

Emotional stress, using the social defeat paradigm in male rats, increased OT release from the SON and anterior ventrolateral hypothalamus [44]. Additionally, OT is liberated upon chronic stress through elevated GC levels as a result of the activated the HPA axis [45]. Steroids are capable of crossing the blood brain barrier. They are therefore ideal peripheral mediators of central events. The forced swim test model of stress in rats increased both VP and OT expression in the magnocellular PVN neurons but not in the SON [46]. While the PSS model of PTSD increased hippocampal OTR, mRNA expression and plasma OT levels were similar to high-dose corticosterone and norepinephrine treatment [39]. Again, these results are comparable to previous studies, demonstrating that corticosterone increases OTR binding and function in the rat hippocampus [47] [48].

In humans, endogenous OT has a great role in various behaviours including social recognition, bonding, maternal behavior and positive communication [49] [50]. It was found that persons with lower baseline OT levels had higher level of distrust [51]. Furthermore, it was found that healthy males who received intranasal OT prior to stressor showed less increase in cortisol level compared to individuals without prior OT treatment [52]. Intranasal OT was found to protect against social stress and to suppress amygdala hyper-responsiveness to emotional stimuli [52] [53].

OT decreased GR expression and increased MR expression in most areas of the hippocampus of the rats, as reported previously [54]. This suggests that the long-term effects of OT are mediated through decreased expression of GR in the 
hippocampus. Both MR and GR receptors showed different localization in the brain, MR receptors are mainly found in the limbic areas, amygdala and expressed intensely in the hippocampus. GR is expressed mainly in PVN and all fields of hippocampus except its cornu ammonis-3 (CA3) region that mainly express MR [55]. MR has high affinity for corticosterone even in absence of stress, GR, on the other hand, has much lower affinity for corticosterone and becomes active only after exposure to stress. GR activation and subsequent corticosterone secretion exerts negative feedback on HPA axis through genomic and non-genomic action [56]. Hippocampus exerts a negative control of HPA axis by inhibiting CRH from PVN [57]. Oxytocin was unable to attenuate the increase in glucocorticoid receptors in the CA3 region. This is consistent with both the limited adaptiveness of the GC system in the CA3 region to other steroids [58], and the gross atrophy of the CA3 region associated with PTSD in humans [59].

However, blockade of endogenous OTR by ICV administration of an OT antagonist failed to reverse the inhibition of HPA axis activity observed during parturition [60]. Moreover, in adult male rats, central administration of an OT antagonist did not modify plasma ACTH responses to acute immobilisation stress [61]. Therefore, the effect of OT on HPA axis activity may depend on the physiological or experimental conditions. OT is known to potentiate CRH effects on the anterior lobe.

OT exerts effects also on the adrenal medulla. It was shown that chronic OT treatment leads to increased epinephrine and norepinephrine the rat adrenal medulla [62]. Moreover, it exerts bidirectional effects on the adrenal cortex where increased corticosterone levels were associated with acute OT administration. On the other hand, chronic OT treatment was able to decrease volumes of all cortical subregions and parenchyma [63] [64]. Since the adrenal medulla is mostly devoid of OTR, these effects may be indirect, mediated through the sympathetic nervous system. This assumption is supported by the fact that OT knockout mice [65] and OTR knockout mice [66] did not show altered stress response while sexual, maternal or social behaviors were greatly affected in such animals.

\section{Conclusion}

The existence OT has been known for over 100 years; however, there are still many unanswered questions regarding its effects. Oxytocinergic functions are controlled by steroid hormones. Details on functional properties of steroids in the neuroendocrine system are still unknown to a large extent. This is especially true for rapid steroid effects on the neuronal membrane, which apparently are essential for OT release, synapse formation, axonal sprouting and neuronal development. Reproductive functions, mood, behaviour but also central and systemic stress response, depend on the various oxytocinergic systems projecting to the limbic system, to the hypophyseal portal system or to the posterior pituitary lobe. Vegetative functions and their control through gonadal and adrenal stero- 
ids may also depend directly or indirectly on OT. Given this extensive level of interaction, it is difficult to conceive how the oxytocinergic system can function in humans. Steroids dramatically affect OT systems in rodents. Chances are that the same is true for other mammalian species. It seems likely that they have similar influences also in humans. This may be of importance for understanding and perhaps also for therapy of stress related human health conditions including cardiac dysfunctions or affective disorders.

\section{Declaration of Interest}

The authors declare that there is no conflict of interest.

\section{References}

[1] Brown, G.W. (1989) Life Events and Illness. Unwin Hyman, London.

[2] Dalgard, O.S., Dowrick, C., Lehtinen, V., Vazquez-Barquero, J.L., Casey, P., Wilkinson, G., Ayuso-Mateos, J.L., Page, H. and Dunn, G. (2006) Negative Life Events, Social Support and Gender Difference in Depression: A Multinational Community Survey with Data from the ODIN Study. Social Psychiatry and Psychiatric Epidemiology, 41, 444-451. https://doi.org/10.1007/s00127-006-0051-5

[3] Mayer, E.A. and Fanselow, M.S. (2003) Dissecting the Components of the Central Response to Stress. Nature Neuroscience, 6, 1011-1012. https://doi.org/10.1038/nn1003-1011

[4] Bear, M.F. (2001) Neuroscience Exploring the Brain. Williams \& Wilkins, Lippincott.

[5] Jirikowski, G., Rodewald, A. and Caldwell, J. (2016) Corticosteroid Binding Globulin (CBG) in Central, Systemic and Cellular Response to Stress. Current Review Endocrinology, 8, 91-98.

[6] Link, H., Dayanithi, G., Föhr, K. and Gratzl, M. (1992) Oxytocin at Physiological Concentrations Evokes Adrenocorticotropin (ACTH) Release from Corticotrophs by Increasing Intracellular Free Calcium Mobilized Mainly from Intracellular Stores. Oxytocin Displays Synergistic or Additive Effects on ACTH-Releasing Factor or Arginine Vasopressin-Induced ACTH Secretion, Respectively. Endocrinology, 130, 2183-2191.

[7] Müller, M.B., Zimmermann, S., Sillaber, I., Hagemeyer, T.P., Deussing, J.M., Timpl, P., Kormann, M.S., Droste, S.K., Kühn, R., Reul, J.M., Holsboer, F. and Wurst, W. (2003) Limbiccorticotropin-Releasing Hormone Receptor 1 Mediates Anxiety-Related Behavior and Hormonal Adaptation to Stress. Nature Neuroscience, 6, 1100-1107. https://doi.org/10.1038/nn1123

[8] Dale, H.H. (1906) On Some Physiological Actions of Ergot. Journal of Physiology, 34, 163-206. https://doi.org/10.1113/jphysiol.1906.sp001148

[9] Swaab, D.F., Nijveldt, F. and Pool, C.W. (1975) Distribution of Oxytocin and Vasopressin in the Rat Supraoptic and Paraventricular Nucleus. Journal of Endocrinology, 67, 461-462. https://doi.org/10.1677/joe.0.0670461

[10] Brownstein, M.J., Russell, J.T. and Gainer, H. (1980) Synthesis, Transport, and Release of Posterior Pituitary Hormones. Science, 207, 373-378. https://doi.org/10.1126/science.6153132

[11] Febo, M., Shields, J., Ferris, C. and King, J. (2009) Oxytocin Modulates Unconditioned Fear Response in Lactating Dams: An fMRI Study. Brain Research, 1302, 
183-193. https://doi.org/10.1016/j.brainres.2009.09.043

[12] Li, X., Schwartz, P. and Rissman, E. (1997) Distribution of Estrogen Receptor-Beta-Like Immunoreactivity in Rat Forebrain. Neuroendocrinology, 66, 63-67. https://doi.org/10.1159/000127221

[13] Tribollet, E., Audigier, S., Dubois-Dauphin, M. and Dreifuss, J.J. (1990) Gonadal Steroids Regulate Oxytocin Receptors but Not Vasopressin Receptors in the Brain of Male and Female Rats. An autoradiographical Study. Brain Research, 12, 129-140. https://doi.org/10.1016/0006-8993(90)90232-Z

[14] Jirikowski, G.F., Caldwell, J.D., Stumpf, W.E. and Pedersen, C.A. (1988) Oxytocinergic Neuronal Systems in the Rat Hypothalamus Are Influenced by Estrogens. Neuroscience, 25, 237-248. https://doi.org/10.1016/0306-4522(88)90022-X

[15] Jirikowski, G.F. (1992) Oxytocinergic Neuronal Systems during Mating, Pregnancy, Parturition, and Lactation. Annals of New York Academy of Science, 652, 253-270. https://doi.org/10.1111/j.1749-6632.1992.tb34360.x

[16] Jirikowski, G.F., RamalhoOrtigao, F.J. and Caldwell, J.D. (1991) Transitory Coexistence of Oxytocin and Vasopressin in the Hypothalamo-Neurohypophysial System of Parturient Rats. Hormone and Metabolic Research, 23, 476-480.

https://doi.org/10.1055/s-2007-1003733

[17] Jirikowski, G.F., McGimsy, W.C., Caldwell, J.D. and Sar, M. (1993) Distribution of Oxytocinergic Glucocorticoid Target Neurons in the Rat Hypothalamus. Hormone and Metabolic Research, 25, 543-544. https://doi.org/10.1055/s-2007-1002171

[18] Sapolsky, R.M., Krey, L.C. and Mcewen, B.S. (1984) Glucocorticoid-Sensitive Hippocampal Neurons Are Involved in Terminating the Adrenocortical Stress Response. Proceeding of National Academy of Science, 81, 6174-6177. https://doi.org/10.1073/pnas.81.19.6174

[19] Herman, J.P., Mcklveen, J.M., Solomon, M.B., Carvalho-Netto, E. and Myers, B. (2012) Neural Regulation of the Stress Response: Glucocorticoid Feedback Mechanisms. Brazilian Journal of Medical and Biological Research, 45, 292-298. https://doi.org/10.1590/S0100-879X2012007500041

[20] Jirikowski, G.F., Pusch, L., Mopert, B., Herbert, Z. and Caldwell, J.D. (2007) Expression of Corticosteroid Binding Globulin in the Rat Central Nervous System. Journal of Chemical Neuroanatomy, 34, 22-28. https://doi.org/10.1016/j.jchemneu.2007.03.007

[21] Mopert, B., Herbert, Z., Caldwell, J.D., et al. (2004) Distribution of Corticosteroid-Binding Globulin in the Rat Hypothalamus, Colocalization with Oxytocin and Vasopressin. FENS Abstracts, 2, A089.011.

[22] Mopert, B., Herbert, Z., Caldwell, J.D., Jirikowski, G.F. and Pusch, L. (2006) Expression of Corticosterone Binding Globulin CBG in the Rat Hypothalamus. Hormone and Metabolic Research, 38, 246-252. https://doi.org/10.1055/s-2006-925344

[23] Berdusco, E.T.M., Yang, K., Hammond, G.L. and John, C. (1995) Corticosteroid-Binding Globulin (CBG) Production by Hepatic and Extra-Hepatic Sites in the Ovine Fetus; Effects of CBG on Glucocorticoid Negative Feedback on Pituitary Cells in Vitro. Journal of Endocrinology, 146, 121-130.

https://doi.org/10.1677/joe.0.1460121

[24] Hammond, G.L., Smith, C.L., Goping, I.S., Underhill, D.A., Harley, M.J., Reventos, J., Musto, N.A., Gunsalus, G.L. and Bardin, C.W. (1987) Primary Structure of Human Corticosteroid Binding Globulin, Deduced from Hepatic and Pulmonary cDNAs, Exhibits Homology with Serine Protease Inhibitors. Proceeding of National Academy of Science, 84, 5153-5157. https://doi.org/10.1073/pnas.84.15.5153 
[25] Jirikowski, G.F., Rodewald, A. and Caldwell, J.D. (2016) Corticosteroid Binding Globulins (CBG) in Central, Systemic and Cellular Stress Response. Current Trend in Endocrinology, 8, 91-98.

[26] Windle, R.J., Kershaw, Y.M., Shanks, N., Wood, S.A., Lightman, S.L. and Ingram, C.D. (2004) Oxytocin Attenuates Stress-Induced c-fos mRNA Expression in Specific Forebrain Regions Associated with Modulation of Hypothalamo-Pituitary-Adrenal Activity. Journal of Neuroscience, 24, 2974-2982. https://doi.org/10.1523/JNEUROSCI.3432-03.2004

[27] Slattery, D.A. and Neumann, I.D. (2010) Chronicicv Oxytocin Attenuates the Pathological High Anxiety State of Selectively Bred Wistar Rats. Neuropharmacology, 58, 56-61. https://doi.org/10.1016/j.neuropharm.2009.06.038

[28] Lukas, M., Toth, I., Reber, S.O., Slattery, D.A., Veenema, A.H. and Neumann, I.D. (2011) The Neuropeptide Oxytocin Facilitates Pro-Social Behaviour and Prevents Social Avoidance in Rats and Mice. Neuropsychopharmacolgy, 36, 2159-2168. https://doi.org/10.1038/npp.2011.95

[29] Elhabachi, N.M., Maklad, H.M., Dief, A.E. and Jirikowski, G.F. (2008) Role of Oxytocin in the Stress Response in Male and Female Rats. Bulletin of Alexandria Faculty of Medicine, 44, 277-287.

[30] Born, J., Lange, T., Kern, W., McGregor, G.P., Bickel, U. and Fehm, H.L. (2002) Sniffing Neuropeptides: A Transnasal Approach to the Human Brain. Nature Neuroscience, 5, 514-516. https://doi.org/10.1038/nn0602-849

[31] Quintana, D.S., Westlve, L.T., Alnæs, D., Rustan, Ø.G., Kaufmann, T., Smerud, K.T., Mahmoud, R.A., Djupesland, P.G. and Andreassen, O.A. (2016) Low Dose Intranasal Oxytocin Delivered with Breath Powered Device Dampens Amygdala Response to Emotional Stimuli: A Peripheral Effect-Controlled Within-Subjects Randomized Dose-Response fMRI Trial. Psychoneuroendocrinology, 69, 180-188. https://doi.org/10.1016/j.psyneuen.2016.04.010

[32] Havranek, T., Zatkova, M., Lestanova, Z., Bacova, Z., Mravec, B., Hodosy, J., Strbak, V. and Bakos, J. (2015) Intracerebroventricular Oxytocin Administration in Rats Enhances Object Recognition and Increases Expression of Neurotrophins, Microtubule-Associated Protein 2, and Synapsin I. Journal of Neuroscience Research, 93, 893-901. https://doi.org/10.1002/jnr.23559

[33] Smith, A.S. and Wang, Z. (2014) Hypothalamic Oxytocin Mediates Social Buffering of the Stress Response. Biological Psychiatry, 76, 281-288. https://doi.org/10.1016/j.biopsych.2013.09.017

[34] Steinman, M.Q., Duque-Wilckens, N., Greenberg, G.D., Hao, R., Campi, K.L., Sarah, A., Laredo, S.A., et al. (2016) Sex-Specific Effects of Stress on Oxytocin Neurons Correspond with Responses to Intranasal Oxytocin. Biological Psychiatry, 80, 406-414. https://doi.org/10.1016/j.biopsych.2015.10.007

[35] Ludwig, M. and Leng, G. (2006) Dendritic Peptide Release and Peptide-Dependent Behaviours. Nature Reviews Neuroscience, 7, 126-136. https://doi.org/10.1038/nrn1845

[36] Patisaul, H.B., Scordalakes, E.M., Young, L.J. and Rissman, E.F. (2003) Oxytocin, But Not Oxytocin Receptor, Is Regulated by Oestrogen Receptor Beta in the Female Mouse Hypothalamus. Journal of Neuroendocrinology, 15, 787-793.

https://doi.org/10.1046/j.1365-2826.2003.01061.x

[37] Choleris, E., Gustafsson, J.A., Korach, K.S., Muglia, L.J., Pfaff, D.W. and Ogawa, S. (2003) An Estrogen Dependent Four-Gene Micronet Regulating Social Recognition: A Study with Oxytocin and Estrogen Receptor-Alpha and -Beta Knockout Mice. 
Proceeding of National Academy of Science, 100, 6192-6197. https://doi.org/10.1073/pnas.0631699100

[38] Dief, A.E., Caldwell, J.D. and Jirikowski, G.F. (2013) Colocalization of P450 Aromatase and Oxytocin Immunostaining in the Rat Hypothalamus. Hormone and Metabolic Research, 45, 273-276.

[39] Cohen, H., Kaplan, Z., Kozlovsky, N., Gidron, Y., Matar, M.A. and Zohar, J. (2010) Hippocampal Microinfusion of Oxytocin Attenuates the Behavioural Response to Stress by Means of Dynamic Interplay with the Glucocorticoid-Catecholamine Responses. Journal Neuroendocrinology, 22, 889-904.

[40] Kozlovsky, N., Matar, M.A., Kaplan, Z., Zohar, J. and Cohen, H. (2009) A Distinct Pattern of Intracellular Glucocorticoid Related Responses Is Associated with Extreme Behavioral Response to Stress in an Animal Model of Post-Traumatic Stress Disorder. European Neuropsychopharmacology, 19, 759-771.

https://doi.org/10.1016/j.euroneuro.2009.04.009

[41] Winslow, J.T., Noble, P.L., Lyons, C.K., Sterk, S.M. and Insel, T.R. (2003) Rearing Effects on Cerebrospinal Fluid Oxytocin Concentration and Social Buffering in Rhesus Monkeys. Neuropsychopharmacology, 28, 910-908.

https://doi.org/10.1038/sj.npp.1300128

[42] Francis, D.D., Champagne, F.C. and Meaney, M.J. (2000) Variations in Maternal Behaviour Are Associated with Differences in Oxytocin Receptor Levels in the Rat. Journal of Neuroendocrinology, 12, 1145-1148. https://doi.org/10.1046/j.1365-2826.2000.00599.x

[43] Noonan, L.R., Caldwell, J.D., Li, L., Walker, C.H., Pedersen, C.A. and Mason, G.A. (1994) Neonatal Stress Transiently Alters the Development of Hippocampal Oxytocin Receptors. Brain Research Developmental Brain Research, 80, 115-120. https://doi.org/10.1016/0165-3806(94)90094-9

[44] Engelmann, M., Ebner, K., Landgraf, R., Holsboer, F. and Wotjak, C.T. (1999) Emotional Stress Triggers Intrahypothalamic But Not Peripheral Release of Oxytocin in Male Rats. Journal Neuroendocrinolgy, 11, 867-872. https://doi.org/10.1046/j.1365-2826.1999.00403.x

[45] Carter, C.S. and Altemus, M. (1997) Integrative Functions of Lactational Hormones in Social Behavior and Stress Management. Annals of New York Academy of Science, 807, 164-174. https://doi.org/10.1111/j.1749-6632.1997.tb51918.x

[46] Wotjak, C.T., Naruo, T., Muraoka, S., Simchen, R., Landgraf, R. and Engelmann, M. (2001) Forced Swimming Stimulates the Expression of Vasopressin and Oxytocin in Magnocellular Neurons of the Rat Hypothalamic Paraventricular Nucleus. European Journal Neuroscience, 13, 2273-2281. https://doi.org/10.1046/j.0953-816x.2001.01613.x

[47] Liberzon, I., Chalmers, D.T., Mansour, A., Lopez, J.F., Watson, S.J. and Young, E.A. (1994) Glucocorticoid Regulation of Hippocampal Oxytocin Receptor Binding. Brain Research, 650, 317-322. https://doi.org/10.1016/0006-8993(94)91798-1

[48] Liberzon, I. and Young, E.A. (1997) Effects of Stress and Glucocorticoids on CNS Oxytocin Receptor Binding. Psychoneuroendocrinology, 22, 411-422. https://doi.org/10.1016/S0306-4530(97)00045-0

[49] Magon, N. and Kalra, S. (2011) The Orgasmic History of Oxytocin: Love, Lust, and Labour. Indian Journal Endocrinology Metabolism, 15, S156-S161. https://doi.org/10.4103/2230-8210.84851

[50] Ditzen, B., Schaer, M., Gabriel, B., Bodenmann, G., Ehlert, U. and Heinrichs, M. (2009) Intranasal Oxytocin Increases Positive Communication and Reduces Corti- 
sol Levels during Couple Conflict. Biological Psychiatry, 65, 728-731. https://doi.org/10.1016/j.biopsych.2008.10.011

[51] Zak, P.J., Kurzban, R. and Matzner, W.T. (2005) Oxytocin Is Associated with Human Trustworthiness. Hormones and Behaviour, 48, 522-527. https://doi.org/10.1016/j.yhbeh.2005.07.009

[52] Heinrichs, M., Baumgartner, T., Kirschbaum, C. and Ehlert, U. (2003) Social Support and Oxytocin Interact to Suppress Cortisol and Subjective Responses to Psychosocial Stress. Biological Psychiatry, 54, 1389-1398.

https://doi.org/10.1016/S0006-3223(03)00465-7

[53] Domes, G., Heinrichs, M., Glascher, J., Buchel, C., Braus, D.F. and Herpertz, S.C. (2007) Oxytocin Attenuates Amygdala Responses to Emotional Faces Regardless of Valence. Biological Psychiatry, 62, 1187-1190. https://doi.org/10.1016/j.biopsych.2007.03.025

[54] Petersson, M. and Uvnäs-Moberg, K. (2003) Systemic Oxytocin Treatment Modulates Glucocorticoid and Mineralocorticoid Receptor mRNA in the Rat Hippocampus. Neuroscience Letter, 343, 97-100. https://doi.org/10.1016/S0304-3940(03)00334-3

[55] Reul, J.M. and de Kloet, E.R. (1985) Two Receptor Systems for Corticosterone in Rat Brain: Microdistribution and Differential Occupation. Endocrinology, 117, 2505-2511. https://doi.org/10.1210/endo-117-6-2505

[56] Groeneweg, F.L., Karst, H., de Kloet, E.R. and Joels, M. (2011) Rapid Non-Genomic Effects of Corticosteroids and Their Role in the Central Stress Response. Journal of Endocrinology, 209, 153-167. https://doi.org/10.1530/JOE-10-0472

[57] Ulrich-Lai, Y.M. and Herman, J.P. (2009) Neural Regulation of Endocrine and Autonomic Stress Responses. Nature Reviews Neuroscience, 10, 397-409. https://doi.org/10.1038/nrn2647

[58] Young, L.J., Wang, Z., Donaldson, R. and Rissman, E.F. (1998) Estrogen Receptor Alpha Is Essential for Induction of Oxytocin Receptor by Estrogen. Neuroreport, 9 , 933-936. https://doi.org/10.1097/00001756-199803300-00031

[59] Mcewen, B.S. (1997) Possible Mechanisms for Atrophy of the Human Hippocampus. Molecular Psychiatry, 2, 255-262. https://doi.org/10.1038/sj.mp.4000254

[60] Neumann, I.D., Bosch, O.J., Toschi, N., Torner, L. and Douglas, A.J. (2003) No Stress Response of the Hypothalamo-Pituitary-Adrenal Axis in Parturient Rats: Lack of Involvement of Brain Oxytocin. Endocrinology, 144, 2473-2479. https://doi.org/10.1210/en.2003-0037

[61] Nakashima, T., Noguchi, T., Furukawa, T., Yamasaki, M., Makino, S., Miyata, S. and Kiyohara, T. (2001) Brain Oxytocin Augments Stress-Induced Long-Lasting Plasma Adrenocorticotropic Hormone Elevation in Rats. Neuroscience Letters, 321 , 161-164. https://doi.org/10.1016/S0304-3940(01)02548-4

[62] Ple'cas, B., Ugresi'c, N., Hristi'c, M., Popovi'c, A. and Jovovi'c, D. (1989) The Response of Rat Adrenal Medulla to Oxytocin. Archives Internationales De Physiologie Et De Biochimie, 97, 303-308. https://doi.org/10.3109/13813458909075070

[63] Stachowiak, A., Macchi, C., Nussdorfer, G.G. and Malendowicz, L.K. (1995) Effects of Oxytocin on the Function and Morphology of the Rat Adrenal Cortex: In Vitro and in Vivo Investigations. Research in Experimental Medicine, 195, 265-274. https://doi.org/10.1007/BF02576797

[64] Stanić, D., Plećaš-Solarović, B., Mirković, D., Jovanović, P., Dronjak, S., Marković, B., Đorđević, T., Ignjatović, S. and Pešić, V. (2017) Oxytocin in Corticosterone-Induced Chronic Stress Model: Focus on Adrenal Gland Function. Psychneu- 
roendrinology, 80, 137-146. https://doi.org/10.1016/j.psyneuen.2017.03.011

[65] Winslow. J.T. and Insel, T. (2002) The Social Deficits of the Oxytocin Knockout Mouse. Neuropeptides, 36, 221-229. https://doi.org/10.1054/npep.2002.0909

[66] Pobbe, R.L.H., Pearson, B.L., Defensor, E.B., Bolivar, V.J., Young, W. SIII, Lee, H.J., Blanchard, D.C. and Blanchard, R.J. (2012) Oxytocin Receptor Knockout Mice Display Deficits in the Expression of Autism-Related Behaviours. Hormones and Behaviour, 61, 436-444. https://doi.org/10.1016/j.yhbeh.2011.10.010

\section{Abbreviations}

OT: Oxytocin

$\mathrm{CRH}$ : Corticotrophin releasing hormone

ACTH: Adrenocorticotrophic hormone

HPA: Hypothalamic-pituitary-adrenal

VP: Vasopressin

PVN: Paraventricular nucleus

SON: Supraoptic nucleus

OTRs: Oxytocin receptors

CBG: Corticosteroid binding globulin

GCR: Glucocorticoid receptors

GC: Glucocorticoids

MR: Mineralocorticoids

PTSD: Post-traumatic stress disorder 